\title{
CONSIDERAÇÕES SOBRE O DESENVOLVIMENTO DOS DIREITOS DA PERSONALIDADE E SUA APLICAÇÃO ÀS RELAÇÕES DO TRABALHO
}

\author{
FÁBIO SIEBENEICHLER DE ANDRADE*
}

\begin{abstract}
RESUMO: O presente trabalho tem como objetivo o estudo dos Direitos da Personalidade e possibilidade de aplicação no Direito do Trabalho. Inicialmente, tratou-se do desenvolvimento teórico dos Direitos da Personalidade. Após, analisou-se a possibilidade de aplicação dos direitos da personalidade e seus desdobramentos no âmbito das relações de trabalho. PALAVRAS-CHAVE: Direito da personalidade; Relações de trabalho; Direito do trabalho.
\end{abstract}

\begin{abstract}
This paper focuses on the study of personality rights and the possibility of its application in the sphere of the Brazilian Labor Law. At first, a theory development of personality rights was addressed. After that, we analyze the application of personal rights and their implications in the sphere of labor relations.

KEYWORDS: Personality rights; Labor relations; Labor Law.

SUMÁRIO: I. Introdução; II. Evolução dos Direitos da Personalidade: de instrumento pontual de tutela para meio de proteção geral dos interesses da esfera pessoal; III. Direitos da Personalidade e Relações do Trabalho; IV. Conclusão.

SUMMARY: I. Introduction; II. Personality rights evolution: from an isolated safeguard instrument to a means of general protection of personal sphere interests; III. Personality rights and labor relations; IV. Conclusion.
\end{abstract}

\section{INTRODUÇÃO}

Constitui-se em tema fundamental da doutrina, o desenvolvimento dos direitos da personalidade. Poucos são os assuntos de Direito Civil que, em curto espaço de tempo, tiveram uma trajetória tão fulgurante: relegados a uma tratativa tópica na codificação do final do século XIX, como no caso do BGB, ou mesmo ignorados pelo codificador, como no caso brasileiro, alcançaram o status de direito fundamental antes do final do Século XX.

Nesse sentido, no Direito brasileiro os Direitos da Personalidade foram tratados, inicialmente, no art. $5^{\circ}$, X, da Constituição Federal de 1988. Na esfera do Direito Civil, coube ao Código Civil de 2002, nos arts. 11 a 21, introduzir uma tratativa acerca desta matéria.

* Professor titular de Direito Civil da Faculdade de Direito da PUCRS. Professor do Curso de Pós-Graduação da PUCRS. Doutor em Direito pela Universidade de Regensburg - Alemanha. Advogado em Porto Alegre-RS 
A afirmação dos Direitos da Personalidade não se restringe, porém, à topografia e ao seu status. Concebido como instrumento de tutela de interesses tópicos da pessoa, a fim de impedir o ataque de outrem à esfera privada do indivíduo, o Direito da Personalidade passa a ser utilizado também em outros campos, alcançando novas projeções, a fim de regular casos em que a pessoa relaciona-se com terceiros.

Um exemplo recente dessa circunstância constitui a vinculação existente entre os Direitos da Personalidade e o Direito do Trabalho. Sendo este um ramo social do Direito, cujos objetivos iniciais eram precipuamente a tutela dos interesses do trabalhador frente ao empregador, debate-se igualmente a necessidade de proteger a personalidade do empregado, relativamente a novas práticas adotadas no mercado de trabalho.

No Direito brasileiro, não contempla a Consolidação das Leis do Trabalho, ou mesmo a legislação especial, um tratamento específico quanto à proteção da personalidade do empregado. Trata-se de situação que se distingue da de outros países, em que se legislou especificamente sobre esta matéria ${ }^{1}$ e que tem sua explicação no momento histórico em que se desenvolveu a disciplina do Direito do Trabalho na ordem jurídica nacional.

Em face de regra expressa no parágrafo único do art. $8^{\circ}$ da Consolidação das Leis do Trabalho, admite-se que o Direito comum seja fonte subsidiária do Direito do Trabalho no que não for incompatível com os seus princípios fundamentais.

Por conseguinte, sendo o Direito Civil como um dos ramos admitidos como Direito Comum ao Direito do Trabalho, constitui-se em ponto relevante a análise da aplicabilidade dos elementos da teoria dos Direitos da Personalidade, especialmente os elencados no Código Civil de 2002, às relações trabalhistas ${ }^{2}$.

No presente estudo, busca-se, portanto, primeiramente, pontuar os principais momentos da evolução dos Direitos da Personalidade. Neste tópico, cumpre examinar, especialmente, o desenvolvimento da temática dos Direitos da Personalidade, bem como apontar a relevância do reconhecimento de um Direito geral de personalidade no ordenamento nacional. Num segundo momento, analisa-se a relação dos Direitos da Personalidade relativamente a temas pontuais do Direito do Trabalho, em especial para verificar a pertinência do tratamento dado à tutela dos direitos específicos de personalidade no Direito brasileiro.

II. EVOLUÇÃO DOS DIREITOS DA PERSONALIDADE: DE INSTRUMENTO PONTUAL DE TUTELA PARA MEIO DE PROTEÇÃO GERAL DOS INTERESSES DA ESFERA PESSOAL

\section{A) A Construção de uma Teoria dos Direitos da Personalidade}

É possível estabelecer uma preocupação com a defesa de interesses relevantes

\footnotetext{
${ }^{1}$ É o caso do Direito italiano que, no denominado Statuto dei Diritti dei Lavoratori, de 1970, contempla regras específicas sobre a dignidade e liberdade do trabalhador.

${ }^{2}$ Ver, por exemplo, Luiz Eduardo Gunther/Cristina Maria Navarro Zornig, O Direito da Personalidade do Novo Código Civil e o Direito do Trabalho, in O Impacto do Novo Código Civil no Direito do Trabalho, p. 124 e segs., Ed. LTr, 2003.
} 
da esfera pessoal já no Direito Romano. A defesa da honra aparece como um exemplo relevante nesse sentido ${ }^{3}$.

Contudo, o espírito romano era avesso à elaboração de teorias ${ }^{4}$, razão pela qual, muito embora seja defendida a tese de que a teoria dos Direitos da Personalidade remonte a autores do século XVI, como Donellus ${ }^{5}$, o certo é que, somente ao final do Século XIX, foram estabelecidos, pela doutrina, os contornos dos Direitos da Personalidade ${ }^{6}$.

Paulatinamente, passou-se a defender a existência e autonomia desta figura, definida como os direitos que tinham por objeto garantir o domínio sobre a própria esfera pessoal ${ }^{7}$.

Em relação à sua natureza jurídica, os Direitos da Personalidade foram qualificados como sendo direitos privados ${ }^{8}$, considerando-os como direitos subjetivos - absolutos -, que deveriam ser por todos reconhecidos e observados, conferindo ao seu titular poderes de proteção. Além disso, afirmava-se o seu caráter não patrimonial, reconhecendo-se, porém, que eles poderiam ter um conteúdo patrimonial ${ }^{9}$.

Ao mesmo tempo, declarava-se que, em princípio, os Direitos da Personalidade têm como característica a intransmissibilidade ${ }^{10}$. Aceitava-se, no entanto, que em alguns casos tanto o exercício, quanto a substância dos Direitos da Personalidade poderiam ser objeto de transmissão ${ }^{11}$.

Acrescentava-se ainda que os Direitos da Personalidade consistiriam em um direito fundamental subjetivo, sobre o qual estariam fundados todos os direitos subjetivos e que em si abrigava todos os direitos ${ }^{12}$.

Entre as primeiras decisões a respeito do tema, encontra-se, no direito alemão, um caso célebre, de 1899, envolvendo o chanceler Bismarck, cujo corpo foi fotografado no leito de morte, sem autorização, tendo sido proibida pelo Tribunal do Império a

\footnotetext{
${ }^{3}$ Cf. Tiziana Chiusi, A Dimensão abrangente do Direito privado romano, in Direitos fundamentais e direito privado, p. 11, 25, Ed. Almedina, 2007.

${ }^{4}$ Ver, exemplificativamente, Tiziana Chiusi, A Dimensão abrangente do Direito privado romano, p. 15, op. cit.

${ }^{5}$ Ver a respeito, Franz Mutzenbecher, Zur Lehre vom Persönchlichkeitsrecht, p. 15, 1909, Hamburg.

${ }^{6}$ Nesse sentido, ver James Q. Whitman, The Two Western Cultures of Privacy, The Yale Law Journal, 2004, p. 1171 et seq.; Hans Hattenhauer, Grundbegriffe des Bürgerlichen Rechts, p. 14, Beck Verlag, 2. ed., 2000; na doutrina nacional, ver Orlando Gomes, Revista Forense, 1966, v. 216, p. 5; Gustavo Tepedino, A Tutela da Personalidade no Ordenamento Civil-constitucional Brasileiro, in Temas de Direito Civil, p. 23, ed. Renovar.

${ }^{7}$ Cf. Otto Gierke, Deutsches Privatrecht, Erster Band, p. 702, 1936, ed. Inalterada da 1. ed., 1905.

${ }^{8}$ No original: "Die Persönlichkeitsrecht sind Privatrechte”, in Otto Gierke, Deutsches Privatrecht, p. 705, op. cit.

${ }^{9}$ Otto Gierke, Deutsches Privatrechte, p. 706, op. cit. No original: Die Persönlichkeitsrechte sind als solche keine Vermögensrechte. Sie können jedoch gleich den Rechten na anderer Persönlichkeit (den Familienrechten, den Körperschftsrechts u.s.w) einen vermögensrechtlichen Inhalt aus sich entfalten oder in sich aufenhemen.

${ }^{10}$ Cf. Otto Gierke, Deutsches Privatrecht, p. 707, op. cit.

${ }^{11}$ Ver Otto Gierke, Deutsches Privatrecht, p. 707, op. cit

12 Cf: Otto Gierke, Deutsches Privatrecht, p. 703, op. cit. No original: Es ist das einheitliche subjetive Grudrecht, dass alle bensonderen subjektive Rechte fundamentirt um in sie alle hinreinreicht”.
} 
divulgação das fotografias feitas ${ }^{13}$. Vislumbra-se nesse exemplo o germe da afirmação de um dos direitos da personalidade, o direito à imagem da pessoa (Recht am einigem Bild).

Concomitantemente a esta decisão européia, advogava-se, na doutrina norte-americana, o direito à privacidade, 'the right to privacy', em artigo célebre na literatura jurídica ${ }^{14}$, a fim de resguardar uma, então, considerada nova necessidade da pessoa: o direito de estar só ${ }^{15}$.

Se é possível reconhecer que, ao final do século XIX, a natureza jurídica essencial dos Direitos da Personalidade fora delineada, o debate em torno dos seus precisos contornos dogmáticos, porém, ainda não havia cessado plenamente, razão pela qual o Código Civil alemão, de 1900, somente instituiu a disciplina relativa ao nome da pessoa, abstendo-se de qualquer regulamentação geral.

Esta é igualmente a razão para a omissão do Código Civil brasileiro de 1916 em relação à matéria, pois tendo sido o anteprojeto redigido por Beviláqua em 1899, a dogmática dos Direitos da personalidade ainda não se encontrava devidamente difundida.

Observa-se, portanto, que neste estágio se tem apenas uma tutela tópica dos Direitos da Personalidade, em que alguns aspectos são protegidos pela jurisprudência e pelo legislador. De modo que somente nas codificações do século XX, como servem de exemplo o Código Civil italiano de 1942 e o Código Civil português de 1966, houve uma regulação estruturada e geral dos diversos Direitos da Personalidade.

Paralelamente a esta lenta evolução da teoria dos Direitos da Personalidade no Direito Civil, porém, configurou-se a extraordinária evolução do Direito Público no Século XX, representado pelo fato de que a Constituição preocupa-se em dispor sobre temas originariamente pertencentes ao Direito Privado. O objetivo da Constituição deixa de ser, única e exclusivamente, o de estabelecer o Estado de Direito e limitar o poder político e passa a ser o de estabelecer a moldura da atividade dos indivíduos. Ela se transforma seja em centro de direção para a legislação ordinária, como em lei fundamental do Direito privado - e dos demais ramos do Direito. Trata-se de um fenômeno tão relevante, que a ele se atribui o título de publicização do privado. Surge, assim, uma crescente interação da esfera pública com o setor privado, que origina, no Direito privado, uma profunda modificação em relação ao ideário existente no século XIX. Estabelece-se, em suma, entre estas duas áreas uma tensão dialética, que conduz à noção de constante interrelação entre os dois grandes setores do Direito ${ }^{16}$. Emblematicamente, faz-se menção à problemática da constitucionalização do Direito Civil e de seu reverso, a civilização do Direito Constitucional ${ }^{17}$.

\footnotetext{
${ }^{13}$ Cf. RGZ 45 (1900), p. 170-174.

${ }^{14}$ Samuel Warren/Louis Brandeis, The Right to Privacy, in Harvard Law Review, 1890, pg. 193 e segs.

${ }^{15}$ No original: "Recent inventions and business methods call attention to the next step which must be taken for the protection of the person, and for securit to the individual what Judge Cooley calls the right "to be let alone".

${ }^{16}$ Alguns autores propugnaram que se abandonasse a distinção entre Direito Público e Direito Privado em favor de um direito comum (Cf. Martin Bullinger, Derecho Público y Privado, p. 120-171, Madrid, 1976).

L. Raiser, por sua vez, defendeu que o grau de publicidade ou privacidade, seria fundamental para determinar se uma figura pertenceria a um deste dois ramos do Direito. Cf. Die Aufgabe des Privatrechts, p. 223, 1977.

${ }^{17}$ Cf. J.J. Gomes Canotilho, Civilização do Direito Constitucional ou Constitucionalização do Direito Civil, in Estudos em homenagem a Paulo Bonavides, p. 108, 113, ed. Malheiros, 2001.
} 
O tema dos Direitos da Personalidade serve como expressiva ilustração para esta inter-relação entre as esferas da Constituição e da Codificação, pois ao longo do século XX passa a ser ele objeto de tutela constitucional. Emblemática quanto ao novo patamar dos Direitos de Personalidade é a Constituição alemã de 1949, que dispõe, no seu art. $2^{\circ}, \S 1^{\circ}$, sobre o direito ao livre desenvolvimento da personalidade (freie Entfaltung der Persönlichkeit) ${ }^{18}$. De forma ainda mais significativa, a Constituição alemã expressamente positiva a dignidade humana (Menschenwürde) como direito fundamental no art. $1^{\mathrm{o}}, \S 1^{\mathrm{o}^{19}}$

Ainda na vigência do Código Civil de 1916, a matéria dos Direitos da Personalidade tinha sido versada pela doutrina brasileira ${ }^{20}$, e havia sido objeto de tratamento pelo Anteprojeto de Código Civil de 1963, elaborado pelo Professor Orlando Gomes. No entanto, a positivação dos Direitos da Personalidade no Direito brasileiro deu-se somente mediante a Constituição de 1988. Em seu art. 5º, inciso X, faz-se clara menção à inviolabilidade de determinados direitos da personalidade ${ }^{21}$. $\mathrm{O}$ art. $1^{\mathrm{o}}$, inciso III, por sua vez, fixa a dignidade da pessoa humana entre os fundamentos da República.

Mesmo em face da positivação dos Direitos da Personalidade pela Constituição de 1988, ainda faltava uma regulação quanto à matéria no plano infraconstitucional, tendo em vista que os preceitos constitucionais não estabeleciam uma disciplina detalhada acerca do assunto.

O Código Civil de 2002 estabelece uma disciplina da matéria, nos já indicados arts. 11 a 21. Cumpre, assim, verificar até que ponto ela estabelece um regramento acerca da existência de um direito geral da personalidade, bem como, a seguir, da suficiência de seus dispositivos para a regulação das relações de trabalho.

\section{B) A Afirmação de um Direito Geral de Personalidade}

Entre as principais questões deixadas em aberto pelo Código Civil de 2002, quanto à disciplina dos Direitos da Personalidade, está a de que o artigo $12^{22}$ não contém preceito expresso acerca da existência de um Direito geral da Personalidade ${ }^{23}$, isto é,

${ }^{18}$ Cf. Konrad Hesse, Grundzüge des Verfassungsrechts der Bundesrepublik Deutschland, p. 183, 20. ed. 1995.

${ }^{19}$ Segundo a jurisprudência alemã (BverfG 32, 98/108), a dignidade da pessoa humana constitui-se no mais alto valor da Constituição alemã (obersten Wert des Grundgesetzes). Ver a respeito, Gerrit Manssen, Grundrechte, p. 48, Beck, 2000.

${ }^{20}$ Exemplificativamente, ver Pontes de Miranda, Tratado de Direito Privado, vol. 7, ed. Borsoi, 1955; Orlando Gomes, Direitos da Personalidade, in Revista Forense, v. 216, 1966, p. 5; Milton Fernandes, Os Direitos da Personalidade, in Estudos jurídicos em homenagem ao Prof. Caio Mário da Silva Pereira, p. 131, Forense, 1984.

${ }^{21}$ Artigo $5^{\circ}, \mathrm{X}$ - são invioláveis a intimidade, a vida privada, a honra e a imagem das pessoas, assegurado o direito à indenização pelo dano material ou moral decorrente de sua violação.

22 “Art. 12 - Pode-se exigir que cesse a ameaça, ou a lesão, a direito da personalidade, e reclamar perdas e danos, sem prejuízo de outras sanções previstas em lei”.

${ }^{23}$ No Direito alemão, em que o BGB não contém na parte geral capítulo expresso sobre os Direitos da Personalidade, a ideia de um direito geral de personalidade desenvolveu-se precisamente para cumprir esta função ampliativa de tutela dos direitos da personalidade. Ela repousa sobre dois fundamentos: de um lado, na própria Lei Fundamental de 1949, que nos artigos $1^{\circ}$ e $2^{\circ}$ dispõe sobre o direito à dignidade humana (Recht des Einzelnen auf Achtung seiner Menchenwürde) acerca do direito ao livre desenvolvimento da personalidade (Recht des Einzelnen auf Entfaltung seiner individuellen Persönlichkeit. De outro, a jurisprudência 
acerca da existência de um complexo de interesses relativo à esfera pessoal, que é merecedor de proteção, quando se verificar a incidência dos pressupostos estabelecidos pelo ordenamento ${ }^{24}$.

Trata-se de orientação percebida, por exemplo, no Código Civil português, em seu art. $70^{25}$, que claramente faz menção à existência de uma tutela geral da personalidade ${ }^{26}$.

No Direito francês, inseriu-se no Código Civil, no art. 16, regra específica acerca da primazia da pessoa e da tutela de sua dignidade ${ }^{27}$, de um lado inserindo no âmbito do Direito civil a possibilidade de invocação do tema da valoração da pessoa e, de outro, fixando a noção de que o tema da dignidade também concerne ao Direito Civil.

Na doutrina brasileira, há quem considere desnecessária esta solução, em face do reconhecimento no Direito brasileiro da dignidade humana, previsto no artigo $1^{0}$ da Constituição Federal ${ }^{28}$. Com efeito, decorridos vinte anos de vigência da Lei maior, poucos temas encontraram tamanha ressonância no Direito brasileiro, como o do princípio da dignidade da pessoa humana, traduzido como o reconhecimento do valor da pessoa, e de sua eficácia na esfera infra-constitucional ${ }^{29}$.

Contudo, cumpre ponderar que a adoção de um preceito claro no Código Civil acerca da proteção ao Direito geral da personalidade poderia servir, em primeiro lugar, de elemento expresso de conexão relativamente ao princípio da dignidade humana. Além disso, tornaria ainda mais efetiva a proteção dos direitos da personalidade, na medida em que salientaria a existência de uma cláusula geral de tutela, coexistente com os eventuais direitos de personalidade específicos e nominados.

Não haveria, igualmente, qualquer dúvida no sentido de que o sistema de tutela de direitos da personalidade no Direito brasileiro apresenta-se como numerus apertus e não numerus clausus, na medida em que a sistemática do Código Civil consistiu em regular, nos artigos 13 a 21, uma série de situações específicas, tais como o nome, a honra, a imagem e a privacidade.

Por outro lado, a existência de uma cláusula geral de Direitos da personalidade na esfera do Código Civil permitiria resguardar o princípio da dignidade humana para situações efetivamente relevantes. No Direito alemão, muito embora já se tenha

alemã reputa os direitos da personalidade como direito especial (sonstiges Recht), a fim de vinculá-los ao § 823 I do BGB - que considera ato ilícito a lesão a direito especial. Cf. Jauernig, BGB - Bürgerliches Gesetzbuch Kommentar, p. 1031, Beck Verlag, 10. ed., 2003; D. Schwab, Einführung in das Zivilrecht, p. 130, Müller Verlag, 2002.

${ }^{24}$ Nesse sentido, ver Dieter Schwab, Einführung in das Zivilrecht, p. 136, n 296, 15. ed., Müller Verlag., 2002.

25 “Artigo 70 - Tutela Geral da Personalidade.

1: A lei protege os indivíduos contra qualquer ofensa ilícita ou ameaça de ofensa à sua personalidade física ou moral".

${ }^{26}$ Para um exame dos benefícios da noção de um direito geral de personalidade, ver Paulo Mota Pinto, O Direito ao Livre Desenvolvimento da Personalidade, in Boletim da Faculdade de Direito da Universidade de Coimbra, Studia Iuridica, 40, 1999, p. 171. Cf. também, António Menezes Cordeiro, Tratado de Direito Civil Português, parte geral, tomo III, pg. 80 e segs., Almedina, 2004

${ }^{27}$ No original: “Art. 16. La loi assure la primauté de la personne, interdit toute atteinte à la dignité de celle-ci et garantit Le respect de l'être humain dês Le commencement de as vie".

${ }^{28}$ Neste sentido, ver Maria Celina Bodin de Moraes, Danos à pessoa humana, p. 117 et seq., ed. Renovar, 2003.

${ }^{29}$ A respeito, ver, por todos, Ingo W. Sarlet, Dignidade da Pessoa Humana e Direitos Fundamentais, p. 74, 79, e segs., $7^{\text {a }}$ ES, Ed Livraria do Advogado, 2009. 
afirmado que o princípio da dignidade humana constitui-se em valor máximo do sistema, esta circunstância tem levado igualmente a considerar-se que a sua aplicação deva ser feita de forma restritiva ${ }^{30}$.

A solução no sentido de reconhecer a existência de um Direito geral de personalidade no plano infraconstitucional - em especial no Código Civil -, portanto, não se apresenta como supérflua. Ela institui, na esfera do Direito Privado - o que inclui o ramo aqui tratado do Direito do Trabalho -, um instrumentário apto a tutelar de forma efetiva a personalidade humana em todas as suas potencialidades e relativamente a todos os seus eventuais modos futuros de expressão ${ }^{31}$, o que em uma era dinâmica, de constantes mudanças e transformações, constitui-se em uma necessidade.

\section{DIREITOS DA PERSONALIDADE E RELAÇÕES DO TRABALHO}

\section{A) $O$ Direito à Honra}

Em relação à honra, o Código Civil não contempla um artigo expresso. Faz menção indireta ao dano à honra, quando trata do direito à imagem no artigo 20, caput ${ }^{32}$. Melhor teria sido, porém, um tratamento distinto entre o direito à honra, considerado como o bom nome e a reputação da pessoa, e o direito à imagem, no sentido de abranger toda a série de caracterizações da pessoa.

Não se fez, além disso, uma distinção entre duas esferas do direito à honra, a subjetiva e a objetiva: esta, a que envolve a reputação da pessoa, sua respeitabilidade no meio social. Aquela, a que se refere aos sentimentos da pessoa em relação ao seu bom nome, tendo em vista uma eventual lesão sofrida ${ }^{33}$.

Relativamente à honra e sua vinculação às relações do trabalho, tem-se presente que a Consolidação das Leis do Trabalho, no artigo 483, alínea “e”, considera hipótese de despedida indireta a conduta do empregador, ou seus prepostos, que incidir em ato lesivo da honra ou da boa fama do trabalhador ou de pessoas de sua família.

Nesse campo, merece especial referência o tema do assédio moral, caracterizado pela adoção de condutas, pelo empregador, que, de várias formas, expõe o empregado a uma situação degradante ou humilhante ${ }^{34}$.

De forma específica, atenta-se para possíveis ações do empregador capazes de

${ }^{30}$ Cf. Gerrit Manssen, Grundrechte, p. 49, op. cit.

${ }^{31}$ Nesse sentido, ver Paulo Mota Pinto, O Direito ao livre desenvolvimento da personalidade, in Studia Juridica, vol. 40, p. 171 et seq., op. cit. Sobre o tema ver Horst Ehmann, Das Allgemeine Persönlichkeitsrecht, in 50 Jahre Bundesgerichtshof - Festgabe aus der Wissenschaft, p. 613, Beck, 2000.

${ }^{32}$ Art. 20. Salvo se autorizadas, ou se necessárias à administração da justiça ou à manutenção da ordem pública, a divulgação de escritos, a transmissão da palavra, ou a publicação, a exposição ou a utilização da imagem de uma pessoa poderão ser proibidas, a seu requerimento e sem prejuízo da indenização que couber, se lhe atingirem a honra, a boa fama ou a respeitabilidade, ou se se destinarem a fins comerciais".

${ }^{33}$ Um momento representativo do acolhimento desta distinção no Direito brasileiro foi a possibilidade de tutela dos direitos da personalidade da pessoa jurídica, estabelecida na Súmula 227, do Superior Tribunal de Justiça, bem como no artigo 52, do Código Civil.

${ }^{34}$ Sobre este tema, a doutrina é extensa. Ver por exemplo Márcia Novaes Guedes, Terror Psicológico no Trabalho, p. 32, LTr, 2005; Rodolfo Pamplona Filho, Noções conceituais sobre o assédio moral na relação de emprego, in RTDC, vol. 28, 2006, p. 93 e segs.; Cláudio Armando Couce de Menezes, Assédio Moral e seus Efeitos Jurídicos, in Revista de Direito do Trabalho, 108, p. 193 e segs; Luiz Marcelo Figueiras de Góis, Assédio Moral: a nova ameaça à integridade do ambiente de trabalho, in Justiça do Trabalho, 287, p. 36 e segs. 
submeter o trabalhador a uma eventual perseguição ou posição de constrangimento, que possam ser reputadas como violadoras de sua reputação ou sentimentos pessoais.

Na doutrina, associou-se este tipo de conduta à expressão inglesa mobbing, para designar o tipo de situação em que o empregado é atacado, assediado ou agredido moral ou subjetivamente pelo empregador ${ }^{35}$.

Na relação de trabalho, não obstante a existência de natureza contratual do vínculo, pelo qual as partes podem concordar sobre pontes essenciais, não se pode desconhecer a existência de um caráter institucional, no qual predomina uma percepção hierarquizada da relação entre empregador e empregado, em que a empresa permanece como centro de poder ${ }^{36}$.

Há preocupação, porém, no sentido de estabelecer com precisão os contornos deste tipo de conduta, tendo em vista a possibilidade de gerar um grande número de processos judiciais, na medida em que, na atualidade, intensificam-se nas relações de trabalho as pressões e cobranças de metas e objetivos a serem alcançados pelo empregado.

Aponta-se, por exemplo, a necessidade de que as condutas do empregador possuam certos requisitos, tais como a regularidade e a constância, a fim de serem enquadradas como sendo assédio moral ${ }^{37}$, não se podendo configurar em uma situação isolada ou episódica.

Este tipo de circunstância vincula-se, necessariamente, ao exame do exercício dos poderes diretivo e punitivo do empregador, que se encontram expressos nos arts. $2^{\circ}$ e $3^{\circ}$ da Consolidação das Leis do Trabalho.

A jurisprudência tem-se orientado no sentido de afastar algumas pretensões de caracterização de dano à honra, quando considera presente o uso legítimo dos direitos subjetivos do empregador. Nega-se, por exemplo, direito à indenização por dano moral pelo fato de ser declarada publicamente que em uma empresa 'só ficam os melhores ${ }^{, 38}$. Não há, por igual, ofensa à honra do empregado no caso em que a empresa somente permite o acesso ao banheiro em duas pausas na jornada de trabalho, de 5 e 15 minutos, caracterizando-se esta conduta como uso regular do poder diretivo do empregador ${ }^{39}$.

A caracterização do assédio moral, com a devida lesão à honra do empregado, exige condutas que afligem efetivamente a sua reputação, ou são revestidas de caráter humilhante, como são o caso de perseguições desencadeadas pelo empregador, exemplificadas por um tratamento depreciativo, diferenciado em relação aos demais colegas $^{40}$, marcadas por cobranças ofensivas e de extrema rispidez ${ }^{41}$.

\footnotetext{
${ }^{35}$ Ver por exemplo Marcia Novaes Guedes, Terror Psicológico no Trabalho, p. 32, op. Cit.

${ }^{36}$ Ver por exemplo Sandra Negri Cogo, Gestão de Pessoas e a Integridade Psicológica do Trabalhador, p. 116 e segs., p. 155, LTr, 2006.

${ }^{37}$ Márcia Novaes Guedes, Terror Psicológico no Trabalho, p. 35, op. cit.

${ }^{38}$ Cf. RR-7130/2002-900-09-00.8, Rel. Min. Dora Mara da Costa, 8 a Turma do TST.

${ }^{39}$ RR - 1419-2007-001-18-00.1, Rel. Min. Ives Gandra Martins Filho, $7^{\mathrm{a}}$ Turma do TST.

${ }^{40}$ Cf. o seguinte exemplo: "Restou devidamente comprovada a humilhação sofrida pelo autor, assim como as perseguições que passou a sofrer, decorrentes de seu desentendimento com o superintendente da empresa. Também restou demonstrada a publicidade dos atos da reclamada, em diversas ações que causaram humilhações ao autor perante os demais colegas. Desse modo, tem-se como correta a sentença enquanto condenou a reclamada ao pagamento de indenização por danos morais ao autor” (RO 00625-2006-121-04-00-2, TRT - $4^{\text {a }}$ Região)

41 Cf. "O assédio moral no trabalho é espécie do gênero dano moral, sendo também instituto conhecido
} 
Nesse particular, apesar da regulação existente na Consolidação das Leis do Trabalho acerca da possibilidade de despedida indireta, no citado art. 483, alínea “e”, é preciso ter presente que, em muitos casos, o empregado não recorre ao instrumento da despedida indireta ${ }^{42}$. De modo que se reiterar, quanto a este ponto, a invocação da conveniência de uma defendida tutela geral de personalidade, com previsão no Código Civil, a fim de evitar o apelo direto ao princípio da dignidade humana.

\section{B) Direito à Imagem e o uso do Nome}

O Direito à imagem é regulado pelo Código Civil no artigo 20. Em face da leitura do artigo 20, extrai-se que a utilização da imagem somente pode ocorrer se (a) houver o consentimento da pessoa interessada ou dos legitimados para o ato; (b) a exibição for necessária para a administração da justiça ou a manutenção da ordem pública.

Na mesma linha, o artigo 18 do Código dispõe que o nome de outra pessoa somente poderá ser utilizado em propaganda comercial mediante autorização.

Trata-se de dispositivos passíveis de aplicação ao Direito do Trabalho, na medida em que se verifica a possibilidade de utilização, pelo empregador, da imagem ou nome do empregado, ou mesmo, de situação inversa, em que o empregado se valha da do empregador ${ }^{43}$.

Em relação aos pressupostos estabelecidos pelo Código Civil para o uso da imagem ou do nome, impõe-se, inicialmente, a questão de saber se o consentimento ou autorização - deve ser necessariamente expresso ou pode ser tácito. Quanto à necessidade de a manifestação de vontade ser expressa ou tácita, o Código Civil prevê, no artigo 111, que o silêncio importa anuência quando as circunstâncias ou os usos o autorizarem, e não for necessária a declaração de vontade expressa ${ }^{44}$.

Em se tratando de cessão de direito da imagem, há que se ponderar o caráter excepcional desta modalidade de negócio, razão pela qual a sua interpretação deve ser em princípio restritiva. Na jurisprudência do Superior Tribunal de Justiça (STJ), tem sido adotada a orientação, de que não se deve ampliar o disposto em cláusulas contratuais $^{45}$.

como hostilização ou assédio psicológico no trabalho. Configura-se quando o empregado é exposto, pelo empregador-subordinante, a situações humilhantes e constrangedoras durante a jornada laboral, a provocarem no empregado-subordinado sentimento de humilhação, menosprezo e desvalorização. Na espécie, o trabalho exercido pelo reclamante era regido por metas, como costuma ser praxe no setor comercial. Compreende-se que uma empresa, necessitando de resultados para obter sucesso, procure motivar seus empregados, buscando deles extrair a sua máxima produtividade. Todavia, esta prática encontra limites na ordem jurídica, sendo o principal deles o respeito à dignidade do trabalhador. Na situação em apreço, a prova testemunhal indica tratamento com excessiva rispidez, acima dos limites razoáveis de exigência profissional. Tal situação, por certo, causou ao autor desconforto moral, mormente porque os repudiáveis atos foram praticados perante os demais colegas”. (RO 00116-2007-010-04-00-9, Des. Ana Rosa Pereira Sagrilo, J. 04.08.2008, TRT - 4 Região).

${ }^{42}$ Nesse sentido, Rodolfo Pamplona Filho, Noções conceituais sobre o assédio moral na relação de emprego, in RTDC 28, 2006, p. 93, 103.

${ }^{43}$ Nesse sentido, Luiz Eduardo Gunther/Cristina Maria Navarro Zornig, O Direito da Personalidade do Novo Código Civil e o Direito do Trabalho, p. 124, 133, op. cit.

${ }^{44}$ Sobre o tema no Código Civil de 2002, ver Vera Fradera, O Valor do silêncio no novo Código Civil, in Aspectos Controvertidos no novo Código Civil, p. 569, ed. RT, 2003.

${ }^{45}$ Cf. REsp 46420, Rel. Min. Ruy Rosado de Aguiar, 4 a Turma, J. 12.09.1994, in RSTJ 68/358. 
Por conseguinte, somente em situações muito claras deve ser aceito como válido o consentimento tácito em relação à cessão do Direito de imagem, o que corresponde à disposição do referido artigo $111^{46}$. Em um caso, o STJ considerou presente o consentimento tácito ao decidir que, se ocorre a exposição da imagem em cenário público - e na hipótese tratava-se de topless -, não se poderia considerar como indevida a sua divulgação pela imprensa, uma vez que a proteção à privacidade encontraria limite na própria exposição realizada ${ }^{47}$.

Contudo, no que concerne a área do Direito do Trabalho, debate-se ainda mais acirradamente acerca da irrenunciabilidade dos direitos da personalidade ${ }^{48}$, tendo em vista a desigualdade material entre o empregador e o empregado, capaz de propiciar uma simplificação do procedimento de consentimento, ainda mais quando se tem presente o caráter de adesão dos contratos de trabalho ${ }^{49}$.

Ao considerar a viabilidade da renúncia a direitos fundamentais, tem-se condicionado expressamente essa possibilidade ao caráter inequívoco do consentimento, a fim de que dele se extraia a determinação de renunciabilidade ${ }^{50}$. Além disso, leva-se em consideração a natureza dos direitos fundamentais, bem como a qualidade das partes envolvidas, mais precisamente a questão de saber se se trata de uma relação entre iguais ou uma envolvendo pessoas em desigualdade material ${ }^{51}$.

Nesse quadro, se é certo que o trabalhador possui liberdade para celebrar o contrato de trabalho, há que se ponderar o desequilíbrio de forças existente na relação de trabalho, bem como a natureza do direito que ele renuncia.

A jurisprudência tem seguido esta orientação, exigindo a presença do consentimento do empregado para o uso da imagem ${ }^{52}$, sob pena de configurar violado este direito com a consequente necessidade de reparação ${ }^{53}$.

\footnotetext{
${ }^{46}$ No Direito italiano, por exemplo, não se exclui igualmente a possibilidade de a cessão do direito de imagem ocorrer mediante consentimento tácito. A respeito, ver Antonino Scalisi, Il Diritto alla Riservatezza, p. 51, Giuffrè, 2002.

${ }^{47}$ Cf. REsp 595600/SC, Rel. Min. Cesar Asfor Rocha, $4^{\mathrm{a}}$ Turma, J. 18.03.2004. A ementa é do seguinte teor: "Não se pode cometer o delírio de, em nome do direito de privacidade, estabelecer-se uma redoma protetora em torno de uma pessoa para torná-la imune de qualquer veiculação atinente a sua imagem. Se a demandante expõe sua imagem em cenário público, não é ilícita ou indevida sua reprodução pela imprensa, uma vez que a proteção à privacidade encontra limite na própria exposição realizada”.

${ }^{48}$ Ver, nesse sentido, José Antônio Peres Gediel, A irrenunciabilidade a direitos da personalidade pelo trabalhador, in Constituição, Direitos Fundamentais e Direito Privado, p. 149 e segs., Ed. Livraria do Advogado, 2003.

${ }^{49}$ José Antônio Peres Gediel, A irrenunciabilidade a direitos da personalidade, p. 157, 160, op. cit.

${ }^{50}$ Cf., por exemplo, Jorge Reis Novais, Renúncia a Direitos Fundamentais, in Perspectivas Constitucionais nos 20 anos da Constituição de 1976, vol. I, p. 303, 1996, Coimbra.

${ }^{51}$ Ver, por exemplo, José Carlos Vieira de Andrade, Os Direitos Fundamentais na Constituição Portuguesa de 1976, p. 330, 334 e segs, 3. ed., Almedina, 2004.

${ }^{52}$ Ver, por exemplo, a seguinte ementa: "Indenização pelo uso da imagem. Evidenciado pela prova que as fotos publicadas na lista telefônica contaram com a anuência dos reclamantes e inexistente nos autos qualquer elemento que permita afirmar que a utilização desta imagem nos anúncios da empresa tenha-lhes causado qualquer espécie de dano, não há falar uso indevido da imagem capaz de gerar direito à indenização” (RO 00151-2007-015-04-00-0).

53 "Indenização. Uso indevido do nome. A divulgação, pela internet, do nome do reclamante como professor de curso de graduação oferecido pela universidade, após sua despedida, constitui violação do
} 


\section{C) Direito à Privacidade}

Em seu artigo 21, dispõe o Código Civil sobre a inviolabilidade da vida privada da pessoa natural, afirmando que o juiz, a critério do interessado, adotará as providências necessárias para impedir ou fazer cessar ato contrário ao preceito.

Muito embora seja conhecido o princípio de que a Lei não deva conter definições, é flagrante que em relação à disciplina da tutela da privacidade, a regulação do Código Civil é praticamente ociosa, na medida em que não define, suficientemente, os diversos aspectos desta temática.

No Direito português, por exemplo, encontra-se no art. 80, inciso 2, do Código Civil, regra no sentido de que a extensão da reserva sobre a intimidade da vida privada deve atender à natureza do caso e à condição das pessoas. Além disso, o Código português disciplina expressamente o tema das cartas confidenciais (art. 75$)^{54}$, e de sua publicação (art. 76) ${ }^{55}$. Regula, também, a matéria referente a memórias familiares e a escritos confidenciais (art. 77) ${ }^{56}$. Da simples descrição das hipóteses previstas no Direito português, observa-se que o codificador brasileiro não contribuiu significativamente para o aperfeiçoamento da matéria da tutela da privacidade no Direito Civil.

Nesse contexto, não surpreende a ausência de disposição sobre a aplicação da tutela da privacidade, direito tipicamente pessoal, a um âmbito coletivo e social, como se apresenta o trabalho da pessoa.

Contudo, há que se ter presente que, no Direito europeu, houve expresso reconhecimento, no famoso caso Niemietz contra Alemanha, julgado pela Corte Européia de Direitos Humanos, em 16 de dezembro de 1992, de que o conceito de vida privada abrange o ambiente de trabalho ${ }^{57}$. Com base no art. $8^{\circ}$ da Convenção

direito de imagem, do qual faz parte o nome da pessoa, e que prescinde da prova do dano/prejuízo sofrido, assim como da culpa ou dolo do agente, quando utilizada para fins comerciais, hipótese dos autos (art. 20 do Código Civil). Indenização pelo uso indevido do nome que se mantém”. (RO 0075-2007-333-04-00-9, $7^{\text {a }}$ Turma do TRT da $4^{\text {a }}$ Região, Rel. Des. Maria Inês Cunha Dornelles, J. 20.08.2008).

${ }^{54}$ Artigo 75, inciso 1 - “O destinatário de carta-missiva de natureza confidencial deve guardar reserva sobre o seu conteúdo, não lhe sendo lícito aproveitar os elementos de informação que ela tenha levado ao seu conhecimento".

${ }^{55}$ Artigo 76, inciso 1 - “As cartas missivas confidenciais só podem ser publicadas com o consentimento do seu autor ou com o suprimento judicial desse consentimento; mas não há lugar ao suprimento quando se trate de utilizar as cartas como documento literário, histórico ou biográfico”.

${ }^{56}$ Artigo 77 - “O disposto no artigo anterior é aplicável, com as necessárias adaptações, às memórias familiares e pessoais e a outros escritos que tenham caráter confidencial ou se refiram a à intimidade da vida privada”.

${ }^{57}$ Confira o seguinte trecho do acórdão : «La Cour ne juge ni possible ni nécessaire de chercher à définir de manière exhaustive la notion de "vie privée". Il serait toutefois trop restrictif de la limiter à un "cercle intime" où chacun peut mener sa vie personnelle à sa guise et d'en écarter entièrement le monde extérieur à ce cercle. Le respect de la vie privée doit aussi englober, dans une certaine mesure, le droit pour l'individu de nouer et développer des relations avec ses semblables. Il paraît, en outre, n’y avoir aucune raison de principe de considérer cette manière de comprendre la notion de "vie privée" comme excluant les activités professionnelles ou commerciales: après tout, c'est dans leur travail que la majorité des gens ont beaucoup, voire le maximum d'occasions de resserrer leurs liens avec le monde extérieur. Un fait, souligné par la Commission, le confirme: dans les occupations de quelqu'un, on ne peut pas toujours démêler ce qui relève du domaine professionnel de ce qui en sort. Spécialement, les tâches d'un membre d'une profession libérale peuvent constituer un élément de sa vie à un si haut degré que l'on ne saurait dire en quelle qualité il agit à un moment donné ». Cf. //cmiskp.echr.coe.int., affaire Niemietz v. Allemagne. 
européia de direitos humanos, a referida Corte instituiu o que a doutrina denominou de 'vida privada social's8.

Nesse campo específico, privacidade do trabalhador no ambiente de trabalho, um dos problemas mais comuns no Direito brasileiro concerne à questão das revistas íntimas, a revista pessoal de empregados. Em relação a esta matéria, cumpre verificar se o empregador possui o poder de realizar este tipo de conduta.

Na legislação trabalhista, o art. 373-A, da CLT, instituído pela Lei nº 9.799/99, no capítulo acerca do trabalho da mulher, autoriza a realização de revista pessoal, resguardada a intimidade do empregado ou funcionário ${ }^{59}$. Não obstante a previsão conste neste setor da CLT, trata-se de preceito aplicável de forma indistinta aos trabalhadores.

Trata-se de tema já apreciado pelo Supremo Tribunal Federal, que considerou, em princípio, passível de ser procedida a revista pessoal do empregado, desde que resguarde os atributos de dignidade da pessoa ${ }^{60}$.

Não obstante esta decisão não faça menção expressa à esta denominação, aponta a necessidade de considerar a exigência do respeito ao devido processo legal, tendo em vista a exigência de adequar-se a possibilidade da revista a um procedimento de prévia e adequada divulgação ${ }^{61}$. Esta linha de orientação tem sido seguida pelos tribunais, que, tem considerado lícita a revista nos pertences do empregado, quando adotada conforme procedimentos objetivos ${ }^{62}$.

É certo que esta orientação traçada pelo Supremo Tribunal Federal revela a tendência de compatibilizar a tutela da esfera pessoal do empregado aos interesses de segurança do empregador, merecendo da doutrina a crítica de certa contradição relativamente a situações, em que prevaleceu uma proteção mais extensa ${ }^{63}$.

Contudo, cabe observar que, em relação a este ponto, a orientação brasileira segue, em linhas gerais a existente no direito europeu, em que também se faz presente uma

\footnotetext{
${ }^{58}$ Cf. por exemplo Bernard Beignier, La Protection de la vie privée, in Libertes et droits fondamentaux, p. 187, 204, op. cit.

${ }^{59}$ Art. 373 - A. "Ressalvadas as disposições legais destinadas a corrigir as distorções que afetam o acesso da mulher ao mercado de trabalho e certas especificidades estabelecidas nos acordos trabalhistas é vedado: VI - proceder o empregador ou preposto a revistas intimas nas empregadas ou funcionárias”.

${ }^{60}$ AgReg em AgIn 220.459-2-RJ, Rel. Min. Moreira Alves, $1^{\text {a }}$ Turma, J. 28.09.1999, cuja ementa é a seguinte: “Agravo Regimental. Revista pessoal em indústrias de roupas íntimas. Inexistência, no caso, de ofensa aos incisos II, III, LVII e X do art. $5^{\circ}$ da Constituição”.

${ }^{61}$ Destaque-se o seguinte trecho do voto do Relator, Min. Moreira Alves: “assim sendo, está correto o acórdão recorrido ao salientar que a revista em causa 'não deve ser rotulada de deprimente, aprioristicamente, se colocada em prática com resguardo dos atributos da dignidade da pessoa, sem constrangimentos, mas, de modo previamente divulgado e aprovado pelo empregado da empresa”.

${ }^{62}$ Cf. a seguinte ementa: "Revista nos pertences dos empregados. Não configuração. A revista nos pertences dos empregados, e por vezes, aleatoriamente, nos moldes realizados pela Polícia Federal nos aeroportos, não importa constrangimento, tampouco agressões morais à intimidade, à imagem profissional da trabalhadora ou a quaisquer dos bens protegidos pelo art. 5 X, da CF. Dano moral não configurado”.

${ }^{63}$ Nesse sentido, cf. Paulo Lobo, A Constituicionalização do Direito Civil Brasileiro, in Direito Civil Contemporâneo

- novos problemas à luz da legalidade constitucional -, p. 18, 27, que aponta nesta decisão do STF uma “ausência de padrão” em relação ao julgado proferido no RE 21'5.984-RJ, em que se concedeu dano moral pela violação do direito à privacidade e imagem em face de publicação de fotografia não autorizada.
} 
série de pressupostos para admitir as revistas pessoais do empregado ${ }^{64}$. A linha européia, porém, apresenta-se como mais concludente, no sentido de exigir, expressamente, que a revista do empregado deve pressupor a sua concordância ${ }^{65}$, o que em nosso ordenamento foi apenas objeto de consideração na referida decisão do Supremo Tribunal Federal.

Um outro tópico merecedor de exame consiste no controle sobre o conteúdo das correspondências eletrônicas recebidas e enviadas pelo empregado, bem como o monitoramento dos sites da internet visitados pelos empregados. Incide, aqui, de forma plena, a problemática relativa à difusão dos novos meios tecnológicos no mundo econômico, e de forma mais específica, no ambiente de trabalho, e a sua relação com a defesa dos direitos da personalidade do trabalhador ${ }^{66}$.

Tendo-se presente o extraordinário benefício incorporado pela Internet, e por um de seus instrumentos, o correio eletrônico, à atividade empresarial, constituiu-se em procedimento natural a difusão que este meio alcançou no ambiente de trabalho.

Na doutrina nacional, encontra-se 'a orientação que defende a indisponibilidade dos e-mails do empregado, em face da necessidade de reconhecer-se o direito à privacidade ${ }^{67}$. Como corolário desta opinião, sustenta-se a irrenunciabilidade deste direito do empregado, tendo em vista as características da relação de emprego ${ }^{68}$.

Contudo, a jurisprudência brasileira orienta-se, predominantemente, na direção oposta, considerando viável a verificação de e-mails expedidos pelo empregado, pelo empregador, e, em consequência, validando demissões de funcionários por justa causa, não obstante sejam normalmente acrescidos determinados pressupostos como o aviso prévio aos empregados ${ }^{69}$, ou a configuração de hipóteses graves de quebra de fidúcia, como serve de exemplo a situação em que se flagrou o uso da correspondência eletrônica pelo empregado para o envio de fotos pornográficas ${ }^{70}$.

${ }^{64}$ Nesse sentido, ver por exemplo o artigo $6^{\circ}$ do Estatuto dos Direitos dos Trabalhadores (Statuto dei Diritti dei Lavoratori), lei 300, de 20 de maio de 1970. Segundo este preceito, revistas pessoais dos empregados somente podem ser realizadas quando essenciais para salvaguardar a propriedade da empresa e sob a condição de que sejam feitas na saída do lugar de trabalho, de acordo com um método objeto de seleção e não discriminatório. Além disso, estes requisitos deverão ser aprovados com os representantes sindicais, ou na ausência destes, com a comissão interna de trabalhadores. Cf. www.coordinamentorsur.it. ${ }^{65}$ Nesse sentido, ver Antonino Scalisi, Il Diritto alla Riservatezza, pg. 382, Giuffrè, 2002.

${ }^{66}$ Sobre este tema, ver, por exemplo, Alexandre Agra Belmonte, O Monitoramento da Correspondência Eletrônica nas Relações de Trabalho, p. 63 e segs, LTr, 2004; Regina Ruaro, O Conteúdo essencial dos direitos fundamentais à intimidade e à vida privada na relação de emprego: o monitoramento do correio eletrônico pelo empregador, in Direitos Fundamentais, Informática e Comunicação - algumas aproximações, p. 227 e segs., Livraria do Advogado, 2007.

${ }^{67}$ Cf. Antonio Silveira Neto/Mario Antonio Lobato de Paiva, A Privacidade do trabalhador no meio informático, in Revista de Direito do Trabalho, 2003, p. 22.

${ }^{68}$ Ver por exemplo Sandra Negri Cogo, Gestão de Pessoas e Integridade Psicológica do Empregador, p. 128 e segs., op. cit.

${ }^{69}$ Ver a seguinte ementa: “Agravo de instrumento em recurso de revista - Dano Moral - Justa Causa. O julgado a quo registrou que não fere norma constitucional a quebra de sigilo de e-mail corporativo, sobretudo quando o empregador, previamente, avisa a seus empregados acerca das normas de utilização do sistema e da possibilidade de rastreamento e monitoramente de seu correio eletrônico" (AIRR 1130/2004-047-02-40, $1^{\text {a }}$ Turma do TST, J. 30.11.2007)

${ }^{70}$ Cf. RR 613/2000-013-10-00, $1^{\text {a }}$ Turma do TST, J.10.06.2005, Rel. Min. João Oreste Dalazen; AIRR 1542/2005-055-02-40, $7^{\text {a }}$ Turma do TST, Rel. Min. Ives Gandra Martins Filho, J. 06.06.2008. 
Prevalece a fundamentação de que os meios eletrônicos utilizados pelo empregado pertencem ao empregador, de que cabe a ele o exercício do poder diretivo, previsto no já referido art. $2^{\circ}$ da CLT, acrescido da circunstância do risco para a empresa empregadora em caso de dano propiciado pelas mensagens eventualmente encaminhadas pelo empregado ${ }^{71}$.

É certo que se tem feito a distinção entre o denominado e-mail corporativo, o que equivale a um instrumento de trabalho do empregado, posto à disposição do empregador, em que prevalecem as orientações acima expostas, do e-mail particular, ou pessoal do empregado, o qual, mesmo acessado no terminal da empresa, é resguardado do monitoramento do empregador ${ }^{72}$. Trata-se de posicionamento que encontra respaldo, por exemplo, na jurisprudência francesa, que teve ocasião de fixar o entendimento no sentido de ser inviolável a correspondência particular do empregado, mesmo sendo utilizados os computadores da empresa ${ }^{73}$.

Contudo, cumpre estabelecer critérios para diferenciar o e-mail corporativo do pessoal. No direito francês, debate-se esta circunstância, tendo sido afirmado que se documentos como fichários ou dossiês são elaborados pelo empregado nos meios eletrônicos postos à disposição pelo empregador, gera-se a presunção de que eles possuem caráter profissional $^{74}$.

Também em relação a este tema, verifica-se a necessidade de compatibilizar a existência de um poder disciplinar do empregador com a necessidade de resguardar a privacidade do empregado. O poder diretivo do empregador não pode ser considerado um salvo conduto, um 'abre-te sésamo', a fim de suplantar os direitos da personalidade do empregado ${ }^{75}$, sob pena de restringir-se desmesuradamente esses direitos fundamentais.

No Direito francês, por exemplo, há expressa previsão neste sentido, atualmente no art. L 1121-1, no sentido de que as restrições aos direitos do empregado devem ser justificadas pela natureza da tarefa a ser cumprida, bem como proporcionais ao fim almejado $^{76}$

Nesse sentido, há que prevalecer a orientação que exija do empregador a utilização de procedimentos que orientem o empregado acerca do monitoramento das mensagens eletrônicas, mesmo em se tratando de correspondência comercial. No que

\footnotetext{
${ }^{71}$ Para uma síntese das posições sobre o tema, cf. Regina Ruaro, O Conteúdo essencial dos direitos fundamentais à intimidade e à vida privada na relação de emprego: in, Direitos fundamentais, informática e comunicação, p. 239, op. cit.

${ }^{72}$ Ver nesse sentido as considerações feitas no citado Cf. RR 613/2000-013-10-00, $1^{\text {a }}$ Turma do TST, J. 10.06.2005. Na doutrina, cf. Alexandre Agra Belmonte, O Monitoramento da Correspondência Eletrônica nas Relações de Trabalho, p. 78 e segs., LTr, 2004.

${ }^{73}$ Arrêt Nikon, J. 02.10.2001, in www.courdecassation.fr/jurisprudence_chambre_sociale.

${ }^{74} \mathrm{Cf}$. Agathe Lepage, Le droits de la personnalité confrontés à L'Internet, in libertés et droit fondamentux, p. 243, 261, dalloz, 2008, 14a ed.

${ }^{75}$ Nesse sentido, ver também Ricardo de Paula Alves, Vida Pessoal do Empregado, Liberdade de Expressão e Direitos Fundamentais do Trabalhador, in Revista do Direito do Trabalho, 2001, p. 132.

${ }^{76} \mathrm{O}$ art. L 1121-1 constitui-se em resistematização do art. L 120-2, cujo teor, no original, é o seguinte:

"Nul ne peut apporter aux droits des personnes ET aux libertés individuelles et collectives restrictions que ne seraient pas justifiées para la nature de la tache à accomplir ni proportionnées au but recherché”.
} 
concerne a correspondência privada do empregado, existindo a corroboração desta circunstância, há que se resguardar a privacidade, em linha com o moderno desenvolvimento da matéria. Acresce a necessidade de ponderação, a fim de que as medidas adotadas pelo empregador sejam proporcionais aos fins de controle almejados ${ }^{77}$.

\section{CONCLUSÃO}

A análise dos temas tratados no presente estudo resgata, inicialmente, a longa trajetória dos Direitos da Personalidade, que migram do campo estrito do Direito Civil, para o status de Direito Fundamental, tipificado no art. 5º inciso X, da Constituição Federal.

No Direito privado brasileiro, o Código Civil de 2002 possui o mérito de regular, minimamente, os principais pontos da tutela dos Direitos da Personalidade. Há que se ter presente, porém, que a função de um Código Civil, no século XXI, é tanto a de concretizar o texto constitucional, como também a de servir como instrumento de (co)ordenação do sistema de Direito de Privado.

Em relação aos Direitos da Personalidade, o Código Civil de 2002 não atende a estes objetivos. De um lado, não somente não aprofunda o tratamento dos principais tópicos do Direito da Personalidade, como também não estabelece elementos mínimos de ponderação, a fim de propiciar ao juiz critérios razoavelmente objetivos e seguros para a tutela dos direitos da personalidade. De outro, não cumpre o objetivo de coordenar os temas relativos aos Direitos da Personalidade - alguns ainda se encontram dispersos em leis especiais - o que lhe atribuiria a função de norma centralizadora da ampla gama de figuras ligadas à matéria.

Relativamente à vinculação dos Direitos da Personalidade e os Direitos do Trabalho, observa-se, em linhas gerais, a inexistência de normas concretizantes no Código Civil, que sirvam como elemento impulsionador e agregador do objetivo de proteção dos direitos do empregado, ainda mais tendo presente a função do Direito Civil de norma subsidiária do Direito do Trabalho.

Em consequência, os Direitos da Personalidade do empregado - com a exceção da matéria de revistas íntimas - ainda recebe uma disciplina tópica. Esta circunstância diminui o nível de proteção dos direitos da personalidade do trabalhador, na medida em que ainda não se edificou uma regulamentação precisa para harmonizar os conflitos existentes nesta matéria.

Observa-se, porém, no Direito brasileiro, a tendência jurisprudencial a resguardar em linhas gerais os poderes do empregador, optando-se por uma interpretação moderada da aplicação dos Direitos da Personalidade. Trata-se de uma solução, em certo aspecto, conservadora no sentido de não subverter o pressuposto de subordinação, característica da relação de trabalho.

\footnotetext{
${ }^{77}$ Nesse sentido, cf. a seguinte decisão da 6 a Turma do TRT da $2^{\text {a }}$ Região, cuja ementa é a seguinte: "Justa causa. E-mail caracteriza-se como correspondência pessoal. O fato de ter sido enviado por computador da empresa não lhe retira essa qualidade. Mesmo que o objetivo da empresa seja a fiscalização dos serviços, o poderi diretivo cede ao direito do obreiro à intimidade (CF, art. 5², VIII). Um único e-mail, enviado para fins particulares, em horário de café, não tipifica justa causa. Recurso provido” (RO 2000000387414 Proc. TRT - SP 2000034734-0 - Rel. Juiz Fernando Antônio Sampaio da Silva, J. 03.08.2000), in Revista do Direito do Trabalho, 108, 2002, p. 179.
} 